\title{
Complexes of Poly(L-glutamic acid) with Oligo(ethyleneimine)s and their Quaternary Derivatives: Effect of the Chain Length of the Oligomers on Complexation
}

\author{
Koji Aвe, Mikio KoIde, and Eishun Tsuchida \\ Department of Polymer Chemistry, Waseda University, Tokyo 160, Japan.
}

(Received September 16, 1976)

\begin{abstract}
Poly(L-glutamic acid), (Glu $)_{n}$, forms polyion complexes with various polycations through the Coulombic force. Oligo(ethyleneimine) and (Glu) $)_{n}$ form complexes only in the proper $\mathrm{pH}$ region, i.e., $\mathrm{pH} \approx 5.5$ in an aqueous solution or $4.5<\mathrm{pH}<$ 6.5 in methanol-water mixture (50:50), while their quaternary derivatives, $\mathrm{H}\left(\mathrm{CH}_{2} \mathrm{~N}^{+}\right.$$\left.\mathrm{Me}_{2} \mathrm{CH}_{2} \cdot \mathrm{Cl}^{-}\right)_{n} \mathrm{H}$, make complexes with (Glu $)_{n}$ over the entire $\mathrm{pH}$ range. The $\alpha$-helical structure of $(\mathrm{Glu})_{n}$ is destabilized by such complexation. These complexations involve cooperative interactions of active sites, so that the complex becomes more stable as the chain lengths of oligo(ethyleneimine) and $\mathrm{H}\left(\mathrm{CH}_{2} \mathrm{~N}^{+} \mathrm{Me}_{2} \mathrm{CH}_{2} \cdot \mathrm{Cl}^{-}\right)_{n} \mathrm{H}$. A critical chain length for forming a stable complex is 4-5. Furthermore, these complexes seem to change gradually into a more stable conformational state.
\end{abstract}

KEY WORDS Polyelectrolyte Complex / Poly(L-glutamic acid) /

Polycation / Conformation / Cooperativity / Circular Dichroism /

It is well known that oppositely charged polyelectrolytes interact with each other through the Coulombic force to form a polyion complex in an aqueous medium., ${ }^{1,2}$ We have reported the detailed complexation mechanisms between synthetic polyelectrolytes: the relationship between the dissociation state of poly(carboxylic acid) and the structure of complex, ${ }^{3}$ the existence of cooperative interactions, ${ }^{4}$ and the formation of higher-ordered structures. ${ }^{5}$ However, the effect of the structures of the component polymers on the complexation mechanism has rarely been discussed so far. This type of complexation involving polypeptides has been discussed qualitatively by Zezin and coworkers. ${ }^{6}$ In this paper, we will discuss the effect of fixed carboxylic groups on an $\alpha$-helix different from a random coil structure and of the chain length of oligomeric polycations on the stability of the $\alpha$-helical structure of poly(L-glutamic acid) when it forms complexes with these substances.

\section{EXPERIMENTAL}

\section{Materials}

$$
\text { Poly (L-glutamic acid) }(G l u)_{n} \text {. }
$$

A $0.5-1.0-\%$ aqueous solution of poly(sodium L-glutamate) $\left(\bar{M}_{w}=50000\right)$ was passed through a column, $3 \mathrm{~cm}$ in diameter and $30 \mathrm{~cm}$ in length, filled with an ion exchange resin, Dow Chemical IR-120; the $\mathrm{pH}$ value of the effluence was 3.3. $\mathrm{pH}$ of the solution was then adjusted by partial neutralization of $(\mathrm{Glu})_{n}$ with $0.1-N \mathrm{NaOH}$.

Oligo(ethyleneimine) $\quad \mathrm{H}_{2} \mathrm{~N}(\mathrm{EtNH})_{n} \mathrm{H} . \quad \mathrm{H}_{2} \mathrm{~N}-$ $(\mathrm{EtNH})_{n} \mathrm{H}$ from monomer to hexamer $(n=0-5)$ were purified by distillation in vacuo; diethylamine $\left(55^{\circ} \mathrm{C} / 760 \mathrm{mmHg}\right)$, ethylenediamine $(49-$ $\left.50^{\circ} \mathrm{C} / 49 \mathrm{mmHg}\right)$, diethylenetriamine $\left(97-99^{\circ} \mathrm{C} /\right.$ $17 \mathrm{mmHg})$, triethylenetetramine $\left(128-129^{\circ} \mathrm{C} /\right.$ $8 \mathrm{mmHg})$, tetraethylenepentamine $\left(175-178^{\circ} \mathrm{C} /\right.$ $9 \mathrm{mmHg})$, and pentaethylenehexamine $(180-$ $184^{\circ} \mathrm{C} / 3 \mathrm{mmHg}$ ).

Quaternized Oligo(ethyleneimine) $\mathrm{s}, \mathrm{H}\left(\mathrm{CH}_{2} \mathrm{~N}^{+}\right.$$\left.\mathrm{Me}_{2} \mathrm{CH}_{2} \cdot \mathrm{Cl}^{-}\right)_{n} \mathrm{H} . \quad 1 \mathrm{~mol}$ of $\mathrm{H}_{2} \mathrm{~N}(\mathrm{EtNH})_{n} \mathrm{H} \quad(n=$ $1-5$ ) was dissolved in $100 \mathrm{~cm}^{3}$ of water and methylated with 6.5 -mol formaldehyde and 15 mol formic acid at $110^{\circ} \mathrm{C}$ for two days on an oil bath. The reaction products were quaternized without further purification by heating with an excess of methyl iodide at $85^{\circ} \mathrm{C}$ in ethanol for more than $10 \mathrm{hr}$, and purified by precipitation in methanol/ethyl acetate. The analysis by 
Volhard's method and elementary analysis showed that the quaternization had gone to completion. Trimethylbenzylammonium iodide was used as a monomer.

\section{Measurement of Complexation}

Circular Dichroism $(C D)$. CD spectra of $(\mathrm{Glu})_{n}$ and its complexes were measured in a range of wavelength from 190 to $260 \mathrm{~nm}$ at a concentration of $2.5 \times 10^{-4}$ base $\mathrm{mol} / l$ of $(\mathrm{Glu})_{n}$ by JASCO $\mathrm{J}-20$. Stoichiometric amounts of $(\mathrm{Glu})_{n}$ and $\mathrm{H}_{2} \mathrm{~N}(\mathrm{EtNH})_{n} \mathrm{H} \quad$ or $\quad \mathrm{H}\left(\mathrm{CH}_{2} \mathrm{~N}^{+} \mathrm{Me}_{2} \mathrm{CH}_{2} \cdot \mathrm{Cl}^{-}\right)_{n} \mathrm{H}$ were employed.

Transmittancy. Transmittancy of the mixed solutions of the aqueous solutions of the two component polymers $\left(10^{-3}-5 \times 10^{-2}\right.$ base $\left.\mathrm{mol} / \mathrm{l}\right)$ were measured $5 \mathrm{~min}$ after mixing by a photoelectric colorimeter (Shimadzu-Spectronic 20) at $420 \mathrm{~nm}$. The limit of the error by the difference of the wavelength was $\pm 5 \%$.

Potentiometric Titration. $\mathrm{pH}$ was measured on adding $(\mathrm{Glu})_{n}$ aqueous solution $\left(5 \times 10^{-3}\right.$ base $\mathrm{mol} / l)$ at various $\mathrm{pH}$ values to the aqueous solutions of $\mathrm{H}_{2} \mathrm{~N}(\mathrm{EtNH})_{n} \mathrm{H}$ or $\mathrm{H}\left(\mathrm{CH}_{2} \mathrm{~N}^{+} \mathrm{Me}_{2} \mathrm{CH}_{2}\right.$. $\left.\mathrm{Cl}^{-}\right)_{n} \mathrm{H}\left(5 \times 10^{-2}\right.$ base $\left.\mathrm{mol} / \mathrm{l}\right)$.

Methanol was purified in the usual manner. Water was ion-exchange water (specific resistance $10^{6} \mathrm{ohm} \mathrm{cm}$ ).

\section{RESULTS AND DISCUSSION}

\section{$(\mathrm{Glu})_{n}-\mathrm{H}\left(\mathrm{CH}_{2} \mathrm{~N}^{+} \mathrm{Me}_{2} \mathrm{CH}_{2} \cdot \mathrm{Cl}^{-}\right)_{n} \mathrm{H}$ System}

Figure 1 shows typical circular dichroism spectra (CD) of (Glu $)_{n}$ and its complexes with $\mathrm{H}\left(\mathrm{CH}_{2} \mathrm{~N}^{+} \mathrm{Me}_{2} \mathrm{CH}_{2} \cdot \mathrm{Cl}^{-}\right)_{n} \mathrm{H}$ at $\mathrm{pH}$ 4.8. The $\alpha-$ helical structure of $(\mathrm{Glu})_{n}$ is characterized by two negative peaks at $222 \mathrm{~nm}$ and $208 \mathrm{~nm}$ and a positive peak at $195 \mathrm{~nm}$. Adding monomer, dimer, or trimer of $\mathrm{H}\left(\mathrm{CH}_{2} \mathrm{~N}^{+} \mathrm{Me}_{2} \mathrm{CH}_{2} \cdot \mathrm{Cl}^{-}\right)_{n} \mathrm{H}$, these peaks remain distinct and are only slightly decreased. However, when the tetramer, pentamer, and hexamer are added, these peaks are changed in accordance with the chain length; a peak at $222 \mathrm{~nm}$ is shifted to the longer wavelength and the $208 \mathrm{~nm}$ peak is decreased. In the case of the hexamer, the original peaks are barely visible and new peaks, a negative peak about at $230 \mathrm{~nm}$ and a positive peak about at $200 \mathrm{~nm}$, are observed. In a more concentrated system, $(\mathrm{Glu})_{n}$ forms an insoluble complex with $\mathrm{H}\left(\mathrm{CH}_{2} \mathrm{~N}^{+} \mathrm{Me}_{2} \mathrm{CH}_{2} \cdot \mathrm{Cl}^{-}\right)_{n} \mathrm{H}$ longer than the tetra-

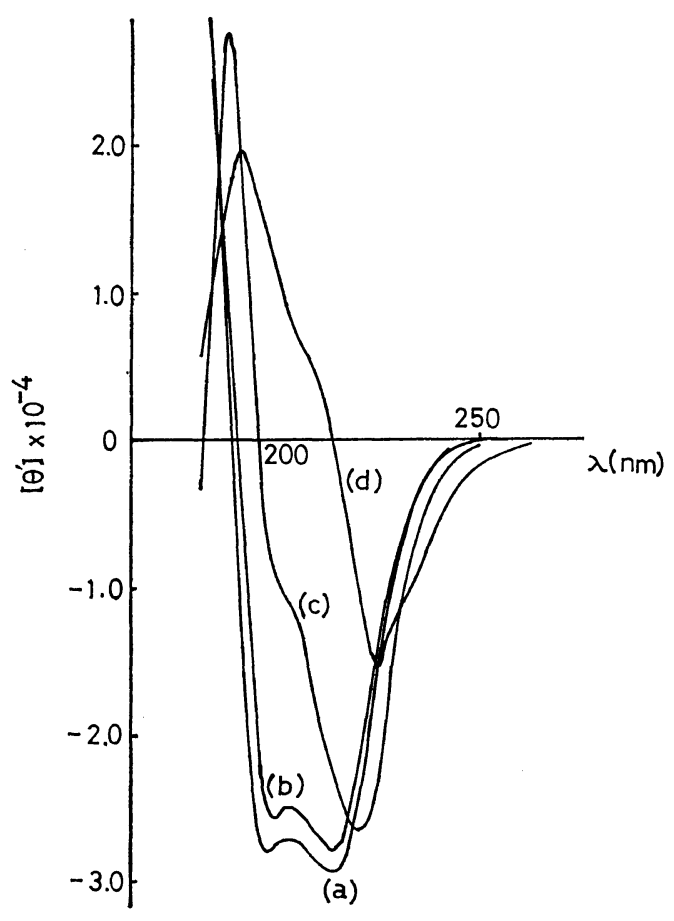

Figure 1. CD spectra of $(\mathrm{Glu})_{n}$ and its complexes with $\mathrm{H}\left(\mathrm{CH}_{2} \mathrm{~N}^{+} \mathrm{Me}_{2} \mathrm{CH}_{2} \cdot \mathrm{Cl}^{-}\right)_{n} \mathrm{H}$ : (a) (Glu $)_{n}$, complexes with $\mathrm{H}\left(\mathrm{CH}_{2} \mathrm{~N}^{+} \mathrm{Me}_{2} \mathrm{CH}_{2} \cdot \mathrm{Cl}^{-}\right)_{n} \mathrm{H}$; (b) $n=2$; (c) $n=4 ;$ (d) $n=6 ;\left[(\mathrm{Glu})_{n}\right]=$ [Oligocation], $2.5 \times$ $10^{-4}$ base $\mathrm{mol} / \mathrm{l}$; at $22^{\circ} \mathrm{C} ; \mathrm{pH}, 4.8$.

mer. From these results, it is found that when (Glu) ${ }_{n}$ forms a complex with $\mathrm{H}\left(\mathrm{CH}_{2} \mathrm{~N}^{+} \mathrm{Me}_{2} \mathrm{CH}_{2}\right.$. $\left.\mathrm{Cl}^{-}\right)_{n} \mathrm{H}$, its $\alpha$-helical structure is destabilized and may be distorted by complexation. When the complex aqueous solutions are made alkaline, their $C D$ spectra are all quite the same as those of the random coil structure of $(\mathrm{Glu})_{n}$; i.e., they contain a positive peak at $217 \mathrm{~nm}$ and a negative one at $197 \mathrm{~nm}$. It seems that the $(\mathrm{Glu})_{\bar{n}}$ oligocation complexes at low $\mathrm{pH}$ do not have the right-handed $\alpha$-helical structure but another oriented structure, while at high $\mathrm{pH}$ they have the random coil structure. In this paper, we will calculate the oriented conformation contents of complexes from the negative peak at $222 \mathrm{~nm}$ or its shifted peaks (see Table II).

Figure 2 shows the dependence of the oriented conformation contents of the complexes on $\mathrm{pH}$ of their solutions. As shown in this figure, conformational transitions, for example, the $\mathrm{pH}$ value at the midpoint of the transition $\left(\mathrm{pH}_{\mathrm{t}}\right)$, 


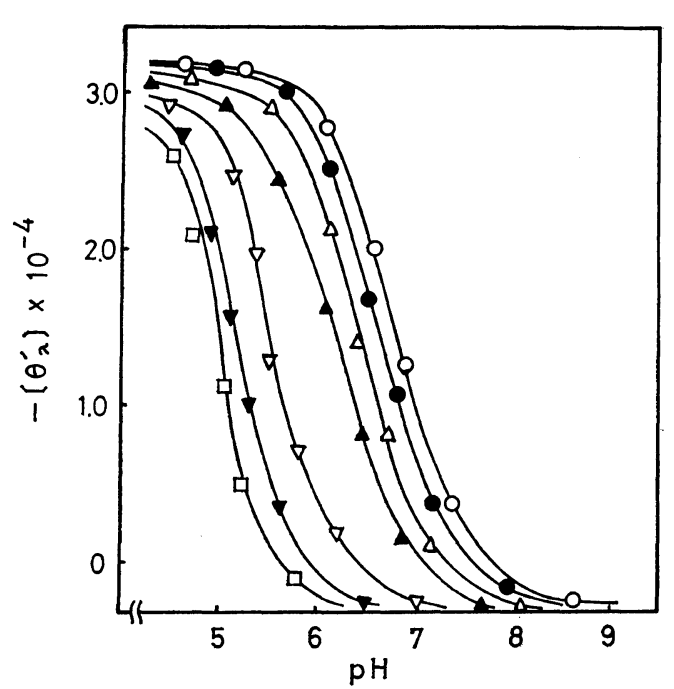

Figure 2. Conformational transitions of $(\mathrm{Glu})_{\bar{n}}$ $\mathrm{H}\left(\mathrm{CH}_{2} \mathrm{~N}^{+} \mathrm{Me}_{2} \mathrm{CH}_{2} \cdot \mathrm{Cl}^{-}\right)_{n} \mathrm{H}$ complexes induced by $\mathrm{pH}$ change from an acidic to an alkaline region: (Glu $)_{n}, \bigcirc$; complexes with $\mathrm{H}\left(\mathrm{CH}_{2} \mathrm{~N}^{+} \mathrm{Me}_{2} \mathrm{CH}_{2}\right.$. $\left.\mathrm{Cl}^{-}\right)_{n} \mathrm{H}, n=1, \bigcirc ; n=2, \triangle ; n=3, \Delta ; n=4, \nabla$; $n=5, \nabla ; n=6, \square ;\left[(\mathrm{Glu})_{n}\right]=[$ Oligocation], $2.5 \times$ $10^{-4}$ base $\mathrm{mol} / l ; 22^{\circ} \mathrm{C}$.

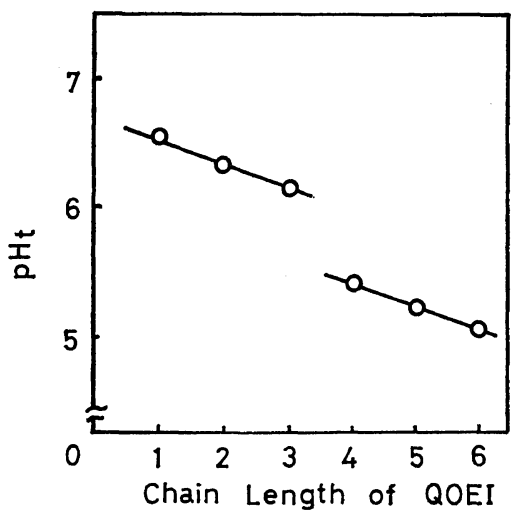

Figure 3. Relationship between $\mathrm{pH}$ at the conformational transition $\left(\mathrm{pH}_{\mathrm{t}}\right)$ and the chain length of $\mathrm{H}\left(\mathrm{CH}_{2} \mathrm{~N}^{+} \mathrm{Me}_{2} \mathrm{CH}_{2} \cdot \mathrm{Cl}^{-}\right)_{n} \mathrm{H} ; \quad\left[(\mathrm{Glu})_{n}\right]=$ [Oligocation], $2.5 \times 10^{-4}$ base $\mathrm{mol} / l ; 22^{\circ} \mathrm{C}$.

are evidently observed in every system. $\mathrm{pH}_{\mathrm{t}}$ decreases with an increase of the chain length of oligocations. The relationship between $\mathrm{pH}_{\mathrm{t}}$ and the chain length of oligocations $(n)$ is shown in Figure 3. When $n$ is less than three, oligocations influence the conformational transition only by the salt effect. Higher homologues $(n>4)$ produce a remarkable lowering of $\mathrm{pH}_{\mathrm{t}}$.

Table I shows apparent dissociation constants $\left(p K_{\mathrm{a}}\right)$ of $(\mathrm{Glu})_{n}$ which forms complexes, obtained from the Henderson-Hasselbach equation. With an increasing concentration of added $\mathrm{NaCl}$, $p K_{\mathrm{a}}$ and $\mathrm{pH}_{\mathrm{t}}$ both decrease, ${ }^{8}$ but oligocations have the same effect at much lower concentrations. In this case, oligocations with more active sites are more effective, but the decrease of $\mathrm{pH}_{\mathrm{t}}$ by the complexation with the oligocations longer than tetramer is not explained only by this phenomenon. The results show that in this system the critical chain length, which is neces-

Table I. Apparent dissociation constants $\left(p K_{\mathrm{a}}\right)$ of $(\mathrm{Glu})_{n}$ and its complexes

\begin{tabular}{llcl}
\hline Additions & $p K_{\mathrm{a}}$ & Additions & $p K_{\mathrm{a}}$ \\
\hline None & $6.2_{3}$ & $\mathrm{NaCl}$ & $5.3_{8}$ \\
$n=1^{\mathrm{a}}$ & $6.1_{4}$ & $n=4^{\mathrm{a}}$ & $5.2_{4}$ \\
$n=2^{\mathrm{a}}$ & $5.7_{6}$ & $n=5^{\mathrm{a}}$ & $5.0_{8}$ \\
$n=3^{\mathrm{a}}$ & $5.4_{5}$ & $n=6^{\mathrm{a}}$ & $4.8_{8}$ \\
\hline
\end{tabular}

a $\mathrm{H}\left(\mathrm{CH}_{2} \mathrm{~N}^{+} \mathrm{Me}_{2} \mathrm{CH}_{2} \cdot \mathrm{Cl}^{-}\right)_{n} \mathrm{H} ;\left[(\mathrm{Glu})_{n}\right], 5.0 \times 10^{-4}$ base $\mathrm{mol} / l ;$;Oligocation], $5.0 \times 10^{-5}$ base $\mathrm{mol} / l ;[\mathrm{NaCl}$, $0.01 \mathrm{~mol} / l ; 25^{\circ} \mathrm{C}$.

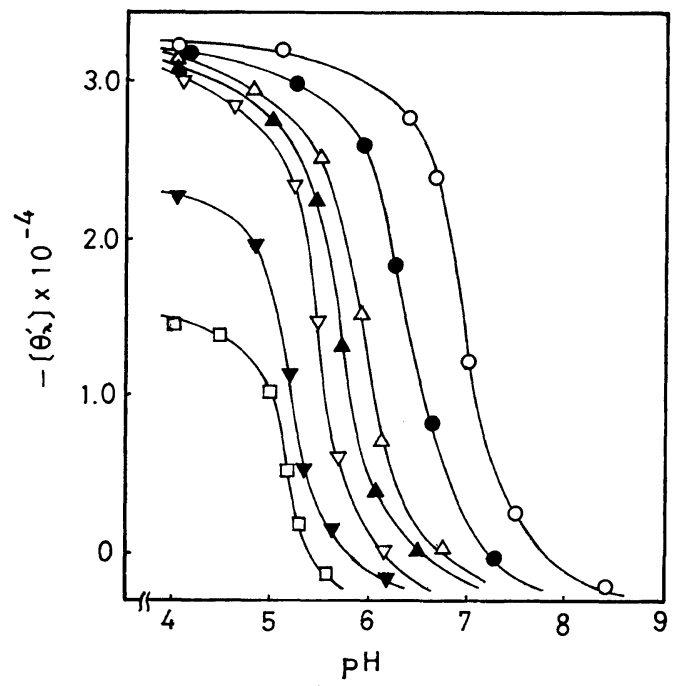

Figure 4. Conformational transitions of (Glu $)_{\bar{n}}$ $\mathrm{H}\left(\mathrm{CH}_{2} \mathrm{~N}+\mathrm{Me}_{2} \mathrm{CH}_{2} \cdot \mathrm{Cl}^{-}\right)_{n} \mathrm{H}$ complexes induced by $\mathrm{pH}$ change from an alkaline to an acidic region: (Glu $)_{n}, \bigcirc$; complexes with $\mathrm{H}\left(\mathrm{CH}_{2} \mathrm{~N}+\mathrm{Me}_{2} \mathrm{CH}_{2}\right.$. $\left.\mathrm{Cl}^{-}\right)_{n} \mathrm{H}, n=1, \bigcirc ; n=2, \triangle ; n=3, \Delta ; n=4, \nabla$; $n=5, \nabla ; n=6, \square ;\left[(\mathrm{Glu})_{n}\right]=$ [Oligocation], $2.5 \times$ $10^{-4}$ base $\mathrm{mol} / \mathrm{l} ; 22^{\circ} \mathrm{C}$. 
Table II. Conformational transition parameters of $(\mathrm{Glu})_{n}$ by complexation ${ }^{\mathrm{a}}$

\begin{tabular}{lccllll}
\hline & \multicolumn{5}{c}{ Complexation $\mathrm{pH}$} \\
\cline { 2 - 7 } Additions & \multicolumn{3}{c}{4.5} & \multicolumn{4}{c}{9.0} \\
\cline { 2 - 7 } & $\mathrm{pH}_{\mathrm{t}}^{\mathrm{c}}$ & $\lambda^{\mathrm{d}}(\mathrm{nm})$ & {$\left[\theta^{\prime}\right]^{\mathrm{e}}$} & $\mathrm{pH}_{\mathrm{t}}{ }^{\mathrm{c}}$ & $\lambda^{\mathrm{d}}(\mathrm{nm})$ & {$\left[\theta_{\lambda^{\prime}}\right]^{\ominus}$} \\
\hline None & $6.8_{0}$ & 222 & $3.2 \times 10^{4}$ & $6.7_{6}$ & 222 & $3.2 \times 10^{4}$ \\
$\mathrm{NH}_{4} \mathrm{Cl}$ & $6.6_{0}$ & 222 & 3.1 & $6.5_{8}$ & 222 & 3.1 \\
Oligocations & & & & & & \\
$n=1$ & $6.5_{6}$ & 222 & 3.1 & $6.5_{3}$ & 222 & 3.1 \\
$n=2$ & $6.3_{3}$ & 222 & 3.1 & $6.1_{7}$ & 222 & 3.1 \\
$n=3$ & $6.1_{6}$ & 222 & 3.1 & $5.7_{0}$ & 223 & 3.1 \\
$n=4$ & $5.4_{2}$ & 226 & 3.1 & $5.5_{1}$ & 227 & 3.1 \\
$n=5$ & $5.2_{5}$ & 227 & 3.0 & $5.3_{0}$ & 230 & 2.5 \\
$n=6$ & $5.0_{9}$ & 230 & 2.9 & $5.1_{3}$ & 233 & 1.5 \\
\hline
\end{tabular}

a $\left[(\mathrm{Glu})_{n}\right]=[$ Oligocation $], 2.5 \times 10^{-4}$ base $\mathrm{mol} / l ; 22^{\circ} \mathrm{C}$.

b Oligocations, $\mathrm{H}\left(\mathrm{CH}_{2} \mathrm{~N}^{+} \mathrm{Me}_{2} \mathrm{CH}_{2} \cdot \mathrm{Cl}^{-}\right)_{n} \mathrm{H}$.

c $\mathrm{pH}_{\mathrm{t}}$, conformational transition $\mathrm{pH}$.

d $\lambda$, a negative peak of each complex.

e $\left[\theta_{\lambda^{\prime}}\right]$, reduced molecular ellipticity at $\lambda \mathrm{nm}$ at $\mathrm{pH}=$ 4.0 .

sary to form a stable complex, is four due to the cooperative interaction of each active site.

Figure 4 shows the conformational transitions of the complexes formed in alkaline solution, while Figure 2 shows the behavior in the acidic region. Table II lists the conformational transition parameters of $(\mathrm{Glu})_{n}$ complexes. The conformational transition induced by $\mathrm{pH}$ change is irreversible and oriented conformations of complexes are more destabilized when the complexes are formed in alkaline solution, where $(\mathrm{Glu})_{n}$ exists in the random coil structure. The following phenomena are observed: 1) a negative peak at $222 \mathrm{~nm}$ of $(\mathrm{Glu})_{n}$ is shifted to the longer wavelength with an increase of the chain length of oligocations; this shift is more pronounced when the complex is prepared in the alkaline region; 2) an oriented conformation, different from the $\alpha$-helical and $\beta$-form structure, is stable only in the acidic region; and 3 ) the conformational transition $\mathrm{pH}\left(\mathrm{pH}_{\mathrm{t}}\right)$ is lowered by complexation.

As shown in Figure 5, the concentration of the oriented conformation decreases with time, especially when the component oligocations of the complex are longer than the tetramer. In these systems, under suitable conditions, a fibrous more highly ordered complex is obtained in one

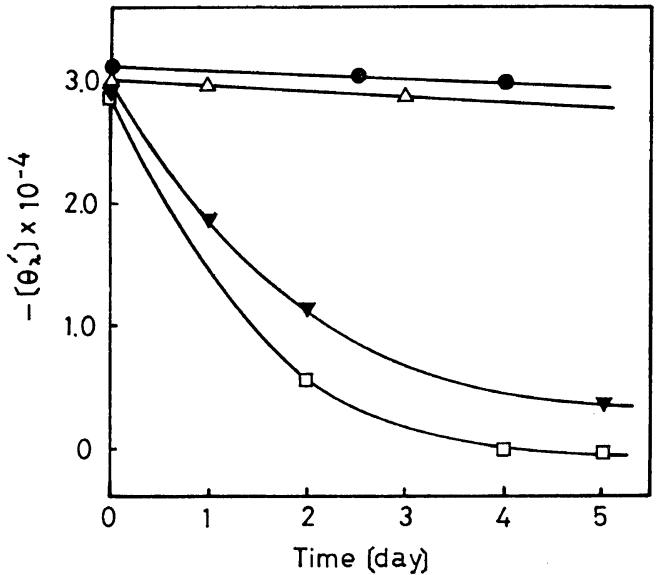

Figure 5. Time dependence of the content of an oriented conformation of $(\mathrm{Glu})_{\bar{n}} \mathrm{H}\left(\mathrm{CH}_{2} \mathrm{~N}+\mathrm{Me}_{2} \mathrm{CH}_{2}\right.$. $\left.\mathrm{Cl}^{-}\right)_{n} \mathrm{H}$ complexes at $\mathrm{pH}=4.8$. The chain length of oligocations: $n=1, \bigcirc ; n=2, \triangle ; n=5, \nabla ; n=6, \square$; $\left[(\mathrm{Glu})_{n}\right]=$ [Oligocation $], 2.5 \times 10^{-4}$ base $\mathrm{mol} / l ; 22^{\circ} \mathrm{C}$.

or two weeks after mixing. ${ }^{9}$ Since complexation through the Coulombic force is a very rapid reaction, distortions seem to exist in the complex and the immediate elimination of these distortions seems to be difficult. So the reorganization of the conformation of the complex to the more stable state is slow.

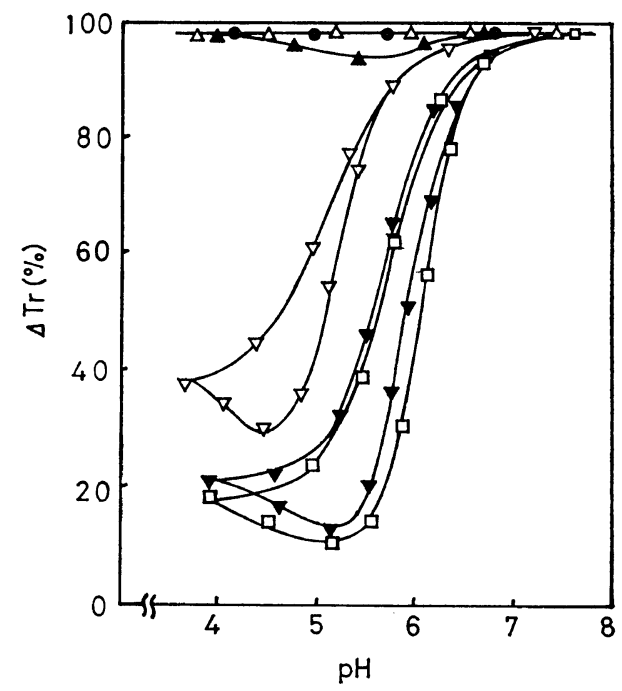

Figure 6. $\mathrm{pH}$ dependence of complexation in the system of (Glu $)_{n}-\mathrm{H}_{2} \mathrm{~N}(\mathrm{EtNH})_{n} \mathrm{H}$ in aqueous medium. The chain length of $\mathrm{H}_{2} \mathrm{~N}(\mathrm{EtNH})_{n} \mathrm{H}: \quad n=0$, ; $n=1, \triangle ; n=2, \Delta ; n=3, \nabla ; n=4, \nabla ; n=5, \square$; $\left[(\mathrm{Glu})_{n}\right]=\left[\mathrm{H}_{2} \mathrm{~N}(\mathrm{EtNH})_{n} \mathrm{H}\right], 10^{-2}$ base $\mathrm{mol} / \mathrm{l} ; 22^{\circ} \mathrm{C}$. 

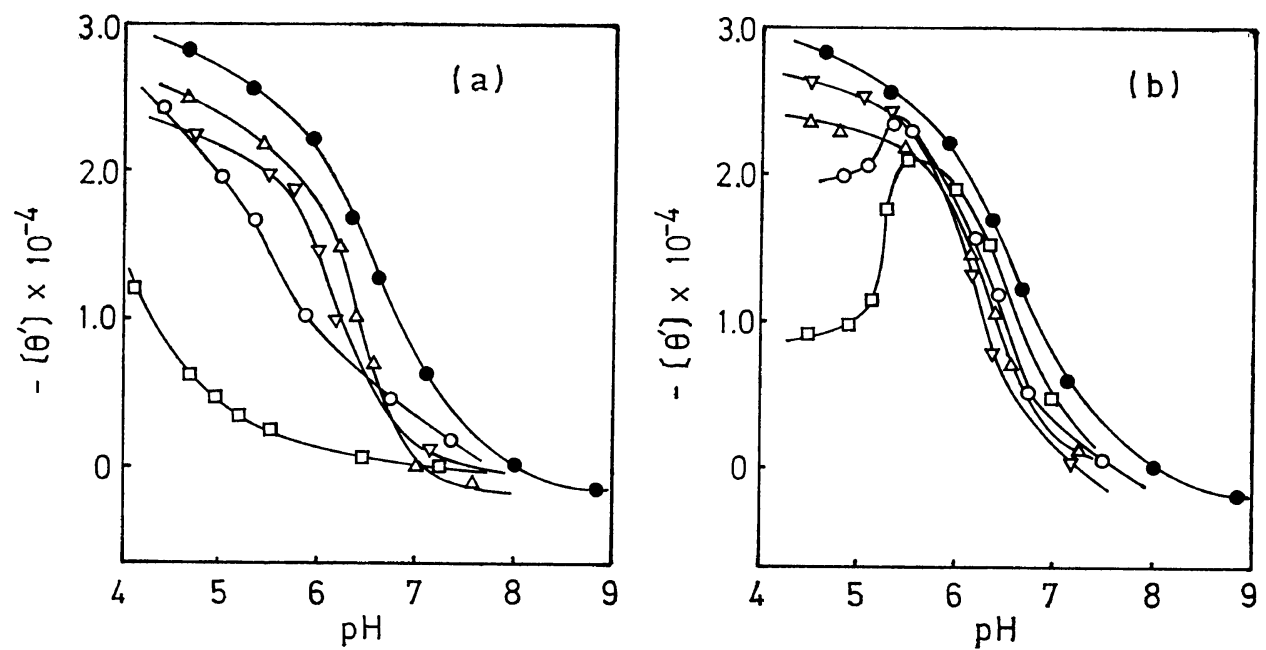

Figure 7. Conformational transitions of $(\mathrm{Glu})_{\bar{n}}-\mathrm{H}_{2} \mathrm{~N}(\mathrm{EtNH})_{n} \mathrm{H}$ complexes in aqueous medium: (a) acid $\longrightarrow$ alkali; (b) alkali $\longrightarrow$ acid; $(\mathrm{Glu})_{n}$, O; complexes with $\mathrm{H}_{2} \mathrm{~N}(\mathrm{EtNH})_{n} \mathrm{H}, n=2, \Delta ; n=3, \nabla$; $n=4, \bigcirc ; n=5, \square ;\left[(\mathrm{Glu})_{n}\right]=\left[\mathrm{H}_{2} \mathrm{~N}(\mathrm{EtNH})_{n} \mathrm{H}\right], 2.5 \times 10^{-4}$ base $\mathrm{mol} / l ; 22^{\circ} \mathrm{C}$.

$(\mathrm{Glu})_{\bar{n}} \mathrm{H}_{2} \mathrm{~N}(\mathrm{EtNH})_{n} \mathrm{H}$ System

Since $(\mathrm{Glu})_{n}$ and $\mathrm{H}_{2} \mathrm{~N}(\mathrm{EtNH})_{n} \mathrm{H}$ are both weak polyelectrolytes, the degree of dissociation of each component polymer is expected to be an important factor for complexation.

Figure 6 shows the relationship between transmittancy and $\mathrm{pH}$ of the mixed aqueous solutions of $(\mathrm{Glu})_{n}$ and oligo(ethyleneimine)s with the chain length from monomer to hexamer. In analogy with the behavior of the $(\mathrm{Glu})_{\bar{n}}$ oligocation systems, a complex is formed only when the oligomeric base is at least the pentamer. However, in contrast to the oligocation systems, $(\mathrm{Glu})_{n}$ and oligomeric bases can react only in a suitable $\mathrm{pH}$ region, $\mathrm{pH} \approx 5.5$, and the formation and the deformation of the complex are almost reversible by a $\mathrm{pH}$ change. Corresponding to this phenomenon, Figure $7(\mathrm{a})$ represents the conformational change with a $\mathrm{pH}$ change from an acidic to an alkaline solution, and (b) represents the data obtained when the $\mathrm{pH}$ is changed in the opposite direction. Considering the dissociation states of both weak component polyelectrolytes, complexation mechanisms can be assumed to be as follows: 1) in an acidic region, oligomeric bases are completely protonated but $(\mathrm{Glu})_{n}$ is scarecely dissociated, so that they can interact with each other only weakly through ion-dipole and/or ion-ion interactions; 2) in the neutral region, both polyelectrolytes are ionized and can interact strongly through ionic bonds; and 3 ) in the alkaline region, $(\mathrm{Glu})_{n}$ is almost dissociated but oligomeric bases are only slightly protonated, so that they cannot interact with each other very much.

As shown in Figure 7(a), since an oligomeric base is protonated at very low $\mathrm{pH}$, the complexation behavior is similar to that of the $(\mathrm{Glu})_{\bar{n}}$-oligocation system, except that only oligomers higher than the pentamer can form the stable complexes (for example, the tetramer of $\mathrm{H}_{2} \mathrm{~N}(\mathrm{EtNH})_{n} \mathrm{H}$ is characterized by $p K_{1}=9.8$, $p K_{2}=9.2, p K_{3}=4.6$, and $p K_{4}=2.8^{10}$ )- Thus the tetramer is below the critical chain length for complexation at $\mathrm{pH} \mathrm{4}$, and it is only with the pentamer that active sites are sufficient to form the complex. That is, the critical number of active sites for complexation is four and the $\alpha$-helical structure of $(\mathrm{Glu})_{n}$ is destabilized by complexation, like $(\mathrm{Glu})_{\bar{n}}$ oligocation systems.

A different situation is observed in Figure 7(b). At high $\mathrm{pH},(\mathrm{Glu})_{n}$ and oligomeric bases cannot interact with each other. When $\mathrm{H}_{2} \mathrm{~N}(\mathrm{EtNH})_{n} \mathrm{H}$ is gradually protonated with a decrease of $\mathrm{pH}$ value, at $\mathrm{pH} 5.5$ the ionic sites of pentamer and hexamer attain the critical number of active sites and begin to form complexes. At the same time, the $\alpha$-helical structure of $(\mathrm{Glu})_{n}$ is destabilized by complexation. The peak of the $\mathrm{CD}$ spectra of these complexes at $222 \mathrm{~nm}$ is also shifted to 


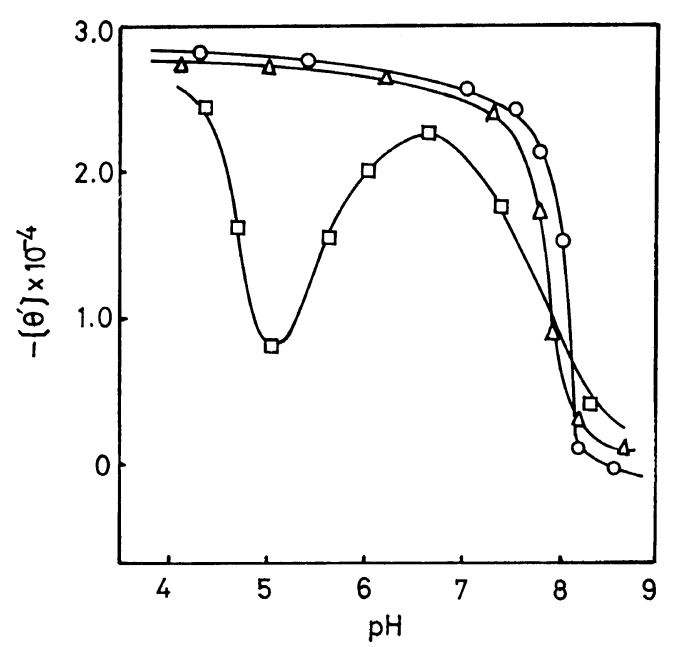

Figure 8. Conformational transitions of $(\mathrm{Glu})_{\bar{n}}$ $\mathrm{H}_{2} \mathrm{~N}(\mathrm{EtNH})_{n} \mathrm{H}$ complexes in water-methanol mixture (50:50): $(\mathrm{Glu})_{n}, \bigcirc$; complexes with $\mathrm{H}_{2} \mathrm{~N}$ $(\mathrm{EtNH})_{n} \mathrm{H}, \quad n=3, \triangle ; n=5, \square ; \quad\left[(\mathrm{Glu})_{n}\right]=\left[\mathrm{H}_{2} \mathrm{~N}-\right.$ $\left.(\mathrm{EtNH})_{n} \mathrm{H}\right], 2.5 \times 10^{-4}$ base $\mathrm{mol} / l ; 22^{\circ} \mathrm{C}$.

the longer wavelength side, to $230 \mathrm{~nm}$, as in the $(\mathrm{Glu})_{\bar{n}}$ oligocation systems as the $\mathrm{pH}$ is made lower.

From these results, it is found that complexes which are formed in an acidic region are difficult to dissociate. On the other hand, in order to make complexes, more than four active sites are necessary. Therefore, the complexation ability and the conformation of the complex at a certain $\mathrm{pH}$ value depend on whether the complex is originally prepared in an acidic or in an alkaline solution.

In other solvents, e.g., 50 vol $\%$ of methanol, complexation is more striking. Figure 8 shows some typical conformational transitions of (Glu)-oligomeric bases complexes. Compared with the $(\mathrm{Glu})_{\bar{n}}$ oligo base system in water, the following differences are observed: 1) the negative peak at $222 \mathrm{~nm}$ is not changed and other peaks are also hardly changed; 2) the direction of the $\mathrm{pH}$ change does not affect the results; 3 ) only the hexamer of oligo base forms a complex with $(\mathrm{Glu})_{n}$; and 4 ) in a low or high $\mathrm{pH}$ region the complex is never formed, while in a suitable $\mathrm{pH}$ region, $4.5<\mathrm{pH}<6.5$, the complex is formed (these absolute $\mathrm{pH}$ values in such organic media are uncertain so that it is impossible to compare them with the ones in water directly, but they are useful for characterising a relative dissociation state in the same medium). These results show that the critical chain length of $\mathrm{H}_{2} \mathrm{~N}(\mathrm{EtNH})_{n} \mathrm{H}$ is six (in reality, it appears that there are only four interacting sites as in water) since the decrease of inductivity of the solution makes it difficult for weak polyelectrolytes to dissociate.

\section{REFERENCES}

1. A. S. Michaels and R. G. Miekka, J. Phys. Chem., 65, 1765 (1961): A. S. Michaels, Ind. Eng. Chem., 57, 32 (1965): A. S. Michaels, L. Mir, and N. S. Schneider, J. Phys. Chem., 69, 1447 (1965).

2. V. B. Rogachova and A. B. Zezin, Vysokomol. Soedin., Ser. B, 11, 327 (1969): ibid., Ser. B, 12, 340 (1970): V. D. Rogachova, A. B. Zezin, and V. A. Kargin, ibid., Ser. B, 12, 826 (1970): A. B. Zezin, V. B. Rogachova, V. A. Kabanov, and V. A. Kargin, ibid., Ser. A, 14, 772 (1972).

3. E. Tsuchida, Y. Osada, and K. Abe, Makromol. Chem., 175, 583 (1974).

4. E. Tsuchida and Y. Osada, ibid., 175, 593 (1974).

5. E. Tsuchida, ibid., 175, 603 (1974).

6. O. A. Aleksina, A. B. Zezin, and I. M. Papisov, Biofizika, 18, 788 (1973).

7. J. C. Leyte and M. Mandel, J. Polym. Sci., Part A, 2, 1879 (1964).

8. N. Kono and A. Ikegami, Biopolymers, 4, 823 (1966): A. Ciferri, L. Rajagh, and J. Hermans, Jr., ibid., 6, 1019 (1968).

9. E. Tsuchida, K. Abe, and M. Honma, Macromolecules, 9, 112 (1976).

10. A. Marxer and K. Miescher, Helv. Chim. Acta, 34, 924 (1951). 